\title{
Pattern of arrhythmias among Nigerians with congestive heart failure
}

This article was published in the following Dove Press journal:

International Journal of General Medicine

26 March 2015

Number of times this article has been viewed

\author{
Olufemi E Ajayi' \\ Olugbenga O Abiodun' \\ Anthony O Akintomide' \\ Rasaaq A Adebayo' \\ Suraj A Ogunyemi' \\ Michael O Balogun' \\ Olaniyi J Bamikole' \\ Adeola O Ajibare' \\ Adesuyi A Ajayi ${ }^{2,3}$ \\ 'Cardiac care unit, Department \\ of Medicine, Obafemi Awolowo \\ University Teaching Hospitals \\ Complex, Ile-Ife, Osun State, Nigeria; \\ ${ }^{2}$ Texas Southern University, Houston, \\ TX, USA; ${ }^{3}$ The Saba University School \\ of Medicine, The Bottom, Saba, Dutch \\ Caribbean
}

Background: In patients with heart failure, death is often sudden due to life-threatening arrhythmias. This work was carried out to evaluate the pattern of arrhythmias in Nigerians with heart failure.

Materials and methods: Thirty subjects with congestive heart failure (CHF), 30 subjects with hypertensive heart disease, and 15 normal subjects with no obvious features of heart disease were evaluated with resting and 24-hour electrocardiographic monitoring and transthoracic echocardiography. Data were analyzed with one-way analysis of variance with post hoc Duncan's analysis, Fisher's exact test, and linear regression analysis using SPSS version 16.

Results: CHF subjects had more instances of supraventricular tachycardia $(P=0.005)$, ventricular extrasystoles $(P<0.001)$, bigeminy $(P<0.001)$, trigeminy $(P<0.001)$, couplets $(P<0.001)$, triplets $(P<0.001)$, and nonsustained ventricular tachycardia $(\mathrm{VT})(P=0.003)$ than the other two control groups. They also showed a significantly longer VT duration (4.6 \pm 5.6 seconds) compared with the other groups $(P<0.001)$. Linear regression analysis showed a significant direct relationship between VT and the maximum number of ventricular extrasystoles per hour $(P=0.001)$.

Conclusion: Cardiac arrhythmias are common in subjects with CHF and are more frequent when compared with patients with hypertensive heart disease and normal subjects.

Keywords: arrhythmias, heart failure, hypertensive heart disease, Nigerians

\section{Introduction}

Heart failure (HF) is a cause of considerable morbidity and mortality worldwide. The prevalence continues to rise because of increasing cardiovascular risks and increasing age. ${ }^{1}$ The prevalence of HF is expected to increase exponentially in sub-Saharan Africa because of the adoption of western lifestyles and other consequences of urbanization. . $^{2,3}$ The causes of HF in sub-Saharan Africa and Nigeria are largely hypertension, cardiomyopathy, and rheumatic valvular heart disease..$^{2,4-7}$ Despite considerable advances in the management of this condition, prognosis still remains grave in patients with $\mathrm{HF}$. Poor prognostic indices include black race, structural heart disease, high New York Heart Association class (III and IV), electrolyte abnormalities, systolic/diastolic dysfunction, and arrhythmias, among many others. ${ }^{8}$ The presence of arrhythmias portends a poorer prognosis because they are independent risk factors for the progression of HF and sudden cardiac death. ${ }^{8}$ Basic tools to identify these arrhythmias include resting electrocardiogram (ECG) with impreciseness, and 24-hour Holter ECG monitoring for precise diagnosis. Studies using Holter monitoring for the precise diagnosis of arrhythmias have been carried out in Nigeria, but none to the best of our knowledge have studied its importance in patients with $\mathrm{HF}^{9-11}$ in comparison with hypertensive heart disease
Correspondence: Olufemi E Ajayi

Cardiac care unit, Department

of Medicine, Obafemi Awolowo

University Teaching Hospitals Complex,

PMB 5538 lle-Ife, Osun State, Nigeria

Tel +2348037I35360

Email oeajayi99@hotmail.com 
(HHD) and apparently healthy individuals. It is the aim of this study to ascertain, with the aid of Holter monitoring, how frequent arrhythmias are, their pattern, and the factors that predict their occurrence in Nigerian HF patients.

\section{Materials and methods}

Subjects and age-matched controls were recruited after informed consent and ethical clearance were obtained. In all, 75 individuals were evaluated using history taking, physical examination, resting and 24-hour electrocardiographic monitoring, and transthoracic echocardiography. Thirty subjects with congestive HF (CHF) secondary to hypertension and dilated cardiomyopathy, 30 subjects with HHD, and 15 normal subjects with no features of heart disease were recruited serially and evaluated.

HHD was the cause of CHF in 21 subjects while in nine subjects, dilated cardiomyopathy was the cause of their CHF. According to the New York Heart Association classification, ten subjects were stage II, 12 subjects were stage III, and eight subjects were stage IV. Also, 18 subjects had low ejection fraction (EF) CHF while EF was normal in 12 subjects. Normal controls were recruited serially among those referred for possible cardiac complaints but without heart disease.

Hypertension was diagnosed according to the eighth report of the Joint National Committee on the detection, evaluation, and treatment of high blood pressure. ${ }^{12}$ Subjects with HHD were those with structural cardiac damage resulting from hypertension with no features of $\mathrm{CHF},{ }^{13}$ while $\mathrm{HF}$ was diagnosed using Framingham's criteria ${ }^{14,15}$ and confirmed by cardiac imaging (chest X-ray and echocardiography). Subjects with CHF were receiving frusemide, angiotensinconverting enzyme inhibitors (mainly lisinopril), spironolactone, an anticoagulant (warfarin), and digoxin as indicated. ${ }^{16}$ None of the HF subjects were receiving a beta blocker, amiodarone, or any other antiarrhythmic drug. The hypertensive subjects were mainly receiving angiotensin receptor inhibitors/blockers with thiazide diuretics or a calcium channel blocker (dihydropyridine) with thiazide diuretics. None of the subjects were using any beta blocker in combination with their antihypertensives.

Echocardiography was performed using a Philips HP sonos 4500 ultrasound machine. M-mode, two-dimensional and pulsed, continuous wave and color flow Doppler modalities were performed in accordance with the American Society of Echocardiography recommendations. ${ }^{17-19}$ Cardiac dimensions and left ventricular mass and mass index were calculated using the Devereux cube formula and corrected for body surface area. ${ }^{20}$
Diastolic functions were measured with pulsed wave Doppler, with the sample volume at the tip of the mitral valve leaflets in the apical four-chamber view. The early and peak atrial velocities and their ratio (E/A), as well as isovolumic relaxation time were measured..$^{21,22}$

Ambulatory ECG (AECG) was recorded using a three-channel Schiller MT-103, in compliance with the American College of Cardiology/American Heart Association guidelines for AECG. ${ }^{23}$ The subjects were encouraged to undertake their usual daily activities, but to avoid bathing or bodily contact of water with the electrodes. The 24-hour AECG data were analyzed by Schiller AECG software (serial no-300.04177 and 300.04178) and analysis was confirmed by two physicians. The analysis included the following:

1. Supraventricular extrasystoles (SVES) and supraventricular tachycardia (SVT).

2. Ventricular extrasystoles (VES), including the maximum number of VES in 1 hour (MAXVESPERHR), ventricular couplets, ventricular triplets, ventricular bigeminy or trigeminy, ventricular tachycardia (VT), and R-on-T phenomenon.

3. Sinus tachycardia, sinus bradycardia.

4. Average heart rate.

Ethical approval was obtained from the Obafemi Awolowo University Teaching Hospitals Complex, Ile-Ife, Osun State, Nigeria.

\section{Statistical analysis}

Data analysis was performed by SPSS software (version 16; IBM Corporation, Armonk, NY, USA). Data are expressed as the mean \pm standard deviation, or as numbers and proportions. Oneway analysis of variance with post hoc Duncan's tests were used to test for the mean difference between normal controls, HHD subjects, and CHF subjects. Chi-square and Fisher's exact tests were used for tests of association. Linear regression analysis was used to determine the predictors of VT (as a quantitative variable). A $P$-value $<0.05$ was taken as statistically significant.

\section{Results}

The clinical and ECG characteristics of subjects are shown in Table 1. Seventy-five subjects comprising $30 \mathrm{CHF}$ patients, 30 HHD patients, and 15 subjects with no heart disease were evaluated. In total, 53 (70.7\%) were males and $22(29.3 \%)$ were females, with no significant sex difference in the three groups. Their ages ranged from 21-82 years with similar mean age of $54.4 \pm 11.9$ years in CHF patients, $55.3 \pm 9.5$ years in HHD patients and $50.3 \pm 15.8$ years in normal 
Table I Clinical and echocardiographic characteristics of the subjects

\begin{tabular}{|c|c|c|c|c|}
\hline Variable & $\begin{array}{l}\text { CHF } \\
(n=30)\end{array}$ & $\begin{array}{l}\text { HHD } \\
(n=30)\end{array}$ & $\begin{array}{l}\text { Normal } \\
(n=15)\end{array}$ & $P$-value \\
\hline Age (years) & $54.4 \pm 11.9$ & $55.3 \pm 9.5$ & $50.3 \pm 15.8$ & 0.268 \\
\hline Sex & $\begin{array}{l}19 \text { males, } \\
\text { II females }\end{array}$ & $\begin{array}{l}22 \text { males, } \\
8 \text { females }\end{array}$ & $\begin{array}{l}12 \text { males, } \\
3 \text { females }\end{array}$ & $0.513^{c}$ \\
\hline BMI $\left(\mathrm{kg} / \mathrm{m}^{2}\right)$ & $23.8 \pm 5.9^{a}$ & $29.99 \pm 2.9^{b}$ & $28.06 \pm 3.8^{b}$ & $0.001 *$ \\
\hline LVMI $\left(g / m^{2}\right)$ & $182.6 \pm 78.7$ & $132.5 \pm 50.3$ & $145.3 \pm 137.8$ & 0.160 \\
\hline $\mathrm{DD}(\mathrm{mm})$ & $56.2 \pm I 4.4$ & $51.7 \pm 8.9$ & $46.6 \pm 6.6$ & 0.132 \\
\hline $\mathrm{SD}(\mathrm{mm})$ & $47.5 \pm 15.0^{\mathrm{a}}$ & $31.5 \pm 6.1^{b}$ & $33.7 \pm 3.7^{b}$ & $<0.001 *$ \\
\hline EF (\%) & $35.5 \pm 19.0^{\mathrm{a}}$ & $61.9 \pm 12.2^{b}$ & $55.5 \pm 8.9^{b}$ & $<0.001^{*}$ \\
\hline FS (\%) & $16.72 \pm 10.7^{\mathrm{a}}$ & $34.43 \pm 9.1^{b}$ & $27.19 \pm 7.9^{b}$ & $<0.001 *$ \\
\hline RVD (mm) & $26.7 \pm 10.6$ & $21.5 \pm 5.9$ & $27.3 \pm 7.4$ & 0.143 \\
\hline LAD (mm) & $47.8 \pm 6.0^{\mathrm{a}}$ & $37.4 \pm 6.1^{b}$ & $37.1 \pm 2.6^{b}$ & $<0.001 *$ \\
\hline $\mathrm{AO}(\mathrm{mm})$ & $30.2 \pm 3.5$ & $29.5 \pm 2.9$ & $28.8 \pm 3.6$ & 0.632 \\
\hline
\end{tabular}

Notes: Values are expressed as the mean \pm standard deviation, or as proportions. $* P<0.05$; ${ }^{a, b}$ using Duncan's post hoc test, the figures marked with ${ }^{\mathrm{a}}$ are significantly different from the figures marked with ${ }^{\text {b; }}$ 'Fisher's exact test.

Abbreviations: CHF, congestive heart failure; n, number; HHD, hypertensive heart disease; BMI, body mass index; LVMI, left ventricular mass index; DD, left ventricular internal dimension in diastole; SD, left ventricular internal dimension in systole; $E F$, ejection fraction; FS, fractional shortening; RVD, right ventricular dimension; LAD, left atrial diameter; $A O$, aortic root diameter.

subjects $(P=0.268)$. Subjects with CHF had a significantly lower body mass index (BMI) of $23.8 \pm 5.9 \mathrm{~kg} / \mathrm{m}^{2}$ compared with $29.9 \pm 2.9 \mathrm{~kg} / \mathrm{m}^{2}$ in HHD subjects and $28.1 \pm 3.8 \mathrm{~kg} / \mathrm{m}^{2}$ in normal subjects $(P=0.001)$. CHF subjects also showed a significantly lower EF of $35.5 \% \pm 19.0 \%$ compared with
$61.9 \% \pm 12.2 \%$ in the HHD subjects and $55.5 \% \pm 8.9 \%$ in the normal subjects $(P<0.001)$. The left atrial diameter in CHF subjects was significantly larger at $47.8 \pm 6.0 \mathrm{~mm}$ than in the HHD and normal subjects with a left atrial diameter of $37.4 \pm 6.1$ and $37.1 \pm 2.6$, respectively $(P<0.001)$. No difference was found in terms of left ventricular mass index, left ventricular internal dimension in diastole, and right ventricular diameter in the three groups.

The Holter parameters of subjects are shown in Table 2. The average heart rate of $89.4 \pm 27.1 \mathrm{bpm}$ was significantly higher among the CHF subjects when compared to the other groups $(P=0.012)$. All CHF subjects $(100 \%)$ had VES $(P<0.001)$, with a significantly higher number of VES per hour $(P=0.011)$. Also, CHF subjects showed significantly higher amounts of advanced grades of VES in the form of bigeminy $(P<0.001)$, trigeminy $(P<0.001)$, couplets $(P<0.001)$, and triplets $(P<0.001)$. There was a significantly higher amount of nonsustained VT in CHF subjects (number $[\mathrm{n}]=13 ; 43.3 \%)$ when compared with three (10\%) in the HHD subjects, and only one (6.7\%) in normal subjects $(P=0.003)$. CHF subjects also showed a significantly longer VT duration (4.6 45.6 seconds) compared with the other groups $(P<0.001)$, but no difference was seen in the VT rate between CHF and HHD subjects. No difference was seen in the number of SVES in the three groups, but CHF subjects showed a higher

Table 2 Holter parameters of subjects

\begin{tabular}{|c|c|c|c|c|}
\hline Variable & CHF $(n=30)$ & HHD $(n=30)$ & Normal $(n=15)$ & $P$-value \\
\hline RT (hours) & $23.4 \pm 1.5$ & $23.6 \pm I .1$ & $23.4 \pm 2.3$ & 0.929 \\
\hline Total beats & $167,000.0 \pm 2,301.9$ & $104,000.0 \pm 218.2$ & $|83,000.0 \pm 3,00| .0$ & 0.210 \\
\hline AVHR (bpm) & $89.4 \pm 27.1^{\mathrm{a}}$ & $73.13 \pm 19.6^{b}$ & $75.40 \pm 8.8^{b}$ & $0.012^{*}$ \\
\hline MAXHR (bpm) & $198.7 \pm 76.7^{\mathrm{a}}$ & $139.9 \pm 42.4^{b}$ & $124.5 \pm 20.2^{b}$ & $<0.001 *$ \\
\hline MINSHR (bpm) & $56.17 \pm 18.2$ & $48.5 \pm 7.7$ & $50.0 \pm 9.6$ & 0.075 \\
\hline MAXSHR (bpm) & | $38.63 \pm 52.6$ & $122.80 \pm 30.3$ & $112.60 \pm 31.6$ & 0.108 \\
\hline VES & $30(100 \%)^{\mathrm{a}}$ & $29(46.7 \%)^{b}$ & $14(30 \%)^{b}$ & $<0.00 I^{*, \mathrm{~d}}$ \\
\hline MAXVESPERHR & $583.9 \pm 958.8^{\mathrm{a}}$ & $170.1 \pm 406.5^{b}$ & $6.0 \pm 5.2^{b}$ & $0.01 I^{*}$ \\
\hline Bigeminy & $24(80 \%)^{\mathrm{a}}$ & $5(16.7 \%)^{b}$ & $0(0 \%)^{b}$ & $<0.001^{*, \mathrm{~d}}$ \\
\hline Trigeminy & $22(73.3 \%)^{\mathrm{a}}$ & $8(26.7 \%)^{b}$ & $0(0 \%)^{c}$ & $<0.00 I^{*, \mathrm{~d}}$ \\
\hline Couplet & $28(93.3 \%)^{\mathrm{a}}$ & $14(46.7 \%)^{\mathrm{b}}$ & $4(13.3 \%)^{b}$ & $<0.001^{*, \mathrm{~d}}$ \\
\hline Triplet & $23(76.7 \%)^{\mathrm{a}}$ & $6(20 \%)^{b}$ & I (6.7\%) & $<0.001^{*, \mathrm{~d}}$ \\
\hline VT & $13(43.3 \%)^{\mathrm{a}}$ & $3(10 \%)^{b}$ & I $(6.7 \%)^{\mathrm{b}}$ & $0.003^{*, d}$ \\
\hline VTD (seconds) & $4.6 \pm 5.6^{\mathrm{a}}$ & $0.3 \pm 0.8^{b}$ & $0.1 \pm 0.5^{b}$ & $<0.001 *$ \\
\hline VTR (bpm) & $202.2 \pm 37.8^{\mathrm{a}}$ & $207.00 \pm 7.1^{\mathrm{a}}$ & $140 \pm 0.0^{\mathrm{b}}$ & $0.005^{*}$ \\
\hline SVES & $30(100 \%)$ & $30(100 \%)$ & $14(93.33 \%)$ & $0.200^{d}$ \\
\hline MAXSVESPERHR & $344.3 \pm 475.9$ & $177.6 \pm 580.7$ & $18.9 \pm 57.3$ & 0.093 \\
\hline SVT & $16(53.3 \%)^{a}$ & $8(26.7 \%)^{b}$ & I $(6.7 \%)^{b}$ & $0.005^{*, \mathrm{~d}}$ \\
\hline
\end{tabular}

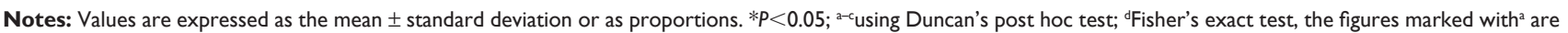
significantly different from the figures marked with ${ }^{\mathrm{b}}$, and the figures marked with ${ }^{\mathrm{b}}$ are significantly different from the figures marked withc.

Abbreviations: bpm, beats per minute; CHF, congestive heart failure; $n$, number; HHD, hypertensive heart disease; RT, recording time; AVHR, average heart rate; MAXHR, maximum heart rate; MINSHR, minimum sinus heart rate; MAXSHR, maximum sinus heart rate; VES, ventricular extrasystoles; MAXVESPERHR, maximum number of ventricular extrasystoles per hour; VT, nonsustained ventricular tachycardia; VTD, duration of ventricular tachycardia; VTR, heart rate of ventricular tachycardia; SVES, supraventricular extrasystoles; MAXSVESPERHR, maximum number of supraventricular extrasystoles per hour; SVT, supraventricular tachycardia. 
number of SVT $(n=16 ; 53.3 \%)$ compared with HHD and normal subjects $(P=0.005)$. The linear regression analysis of the predictors of VT is shown in Table 3 . While age $(P=0.660)$ and septal wall thickness $(P=0.440)$ showed a nonsignificant inverse relationship with VT, BMI $(P=0.732), \mathrm{EF}(P=0.575)$, left ventricular posterior wall thickness $(P=0.257)$, and left ventricular internal dimension in diastole $(P=0.112)$ showed a nonsignificant and direct relationship with VT. However, the maximum number of VE per hour (MAXVESPERHR) showed a significant direct relationship with VT $(P=0.001)$ in that for every MAXVESPERHR in these CHF subjects, the risk of developing VT increases by 0.023 .

\section{Discussion}

This study showed that common arrhythmias in HF subjects included SVES, SVT, VES (including its different forms), and VT. It also showed that these cardiac arrhythmias are more commonly found in HF subjects when compared with HHD and normal subjects. This is similar to findings of the greater risk of ventricular arrhythmias in HF subjects when compared with normal controls by Lasisi et al. ${ }^{24}$ This has been attributed to a multiplicity of mechanisms, the exact nature of which is important to unravel in order to be able to better risk stratify these patients to avoid sudden death. ${ }^{25}$ These mechanisms include early autonomic and repolarization abnormalities, afterdepolarizations, re-entry, and enhanced automaticity. ${ }^{25,26}$ In addition to these, other factors that play modifying roles to reduce the threshold for arrhythmogenesis in HF include electrolyte abnormalities, scar and fibrosis formation, valvular disease, complications of medical management (eg, digoxin toxicity and abnormal electrophysiologic predispositions [QT abnormalities and impaired vagal tone]). ${ }^{17,26,27}$ Higher grades of VES (couplets, triplets, bigeminy, and trigeminy) were found to be

Table 3 Linear regression analysis of predictors of ventricular tachycardia

\begin{tabular}{llll}
\hline Variable & Exp (B) & P-value & Cl \\
\hline Age $($ years) & -0.19 & 0.660 & -1.29 to 0.89 \\
BMI $\left(\mathrm{kg} / \mathrm{m}^{2}\right)$ & 0.28 & 0.732 & -1.75 to 2.32 \\
SWT $(\mathrm{mm})$ & -1.37 & 0.440 & -5.59 to 2.84 \\
PWT $(\mathrm{mm})$ & 2.10 & 0.257 & -2.13 to 6.33 \\
DD $(\mathrm{mm})$ & 0.62 & 0.112 & -0.21 to 1.44 \\
EF $(\%)$ & 0.19 & 0.575 & -0.65 to 1.04 \\
MAXVESPERHR & 0.02 & $0.00 I^{*}$ & $0.01-0.03$ \\
\hline
\end{tabular}

Note: $* P<0.05$.

Abbreviations: $\operatorname{Exp}(\mathrm{B})$, odds ratio; $\mathrm{Cl}$, confidence interval; $\mathrm{BMI}$, body mass index; SWT, septal wall thickness; PWT, Left ventricular posterior wall thickness; DD, left ventricular internal dimension in diastole; EF, ejection fraction; MAXVESPERHR, maximum number of ventricular extrasystoles per hour. significantly higher in our HF subjects compared to the HHD subjects and normal controls. They are important because they are considered to predate the onset of ventricular fibrillation (VF) in those with structural heart disease. ${ }^{28}$

Forty-three percent of CHF subjects in this study had nonsustained VTs, while $10 \%$ of those with HHD also showed nonsustained VTs. This contrasts with a very low number of nonsustained VTs $(0.9 \%)$ in subjects in the study by Omotoso et al. ${ }^{29}$ In their study, they examined the resting ECGs of 2,017 subjects and AECG was not done. This difference shows that AECG is better than resting ECG in the evaluation of arrhythmias in HF and HHD subjects because it is more sensitive and can be used to evaluate the rate, rhythm, and variability of asymptomatic and symptomatic events. ${ }^{30}$

This study also showed higher rates per hour and second of VES and nonsustained VT, respectively, in HF subjects. The roles of the frequency and rate of VES and VT in predicting sudden death have been established. It has been postulated that the increased duration and rate of VT or VES may hasten degeneration to sustained VT and VF, and then to sudden death. ${ }^{31-33}$ Mechanisms such as ischemia, adrenergic stimulation, and increase in blood pressure, particularly in those with extrasystoles, mechanoelectrical dissociation, and abnormal loading have been identified in the literature as predictors of nonsustained VT. ${ }^{34}$ These factors do so by acting as the drivers of hypertrophy or dilation of the heart. ${ }^{34}$ In this study, positive correlations between surrogates of hypertrophy and dilation were seen, though they did not reach statistical significance. This may be due to the relatively small sample size of this study. This study, however, showed that the frequency of VES per hour is a predictor of VT. This is in keeping with studies that have reported a link between this frequency and sudden death, the cause of which is usually sustained VT and VF. ${ }^{31-33,35}$ Also, the presence of ten or more VES per hour has been shown to identify patients at an increased risk for VT or sudden death. ${ }^{36}$

\section{Conclusion}

Cardiac arrhythmias are common in subjects with CHF and are more frequent when compared with HHD and normal subjects. These arrhythmias include nonsustained VT, which can degenerate into life-threatening forms - namely, sustained VT and VF - causing sudden death. Therefore, routine use of AECG to risk stratify and aid in management is essential in all CHF subjects. In this study, HF subjects on antiarrhythmic drugs were excluded. A further study to assess the impact of these drugs (beta blockers and amiodarone) on morbidity and mortality is being carried out. 


\section{Limitations}

The results of this study may be biased by the relatively small sample size.

\section{Disclosure}

The authors report no conflicts of interest in this work.

\section{References}

1. Levy D, Kenchaiah S, Larson MG, et al. Long-term trends in the incidence of and survival with heart failure. N Engl J Med. 2002;347(18): 1397-1402.

2. Mendez GF, Cowie MR. The epidemiological features of heart failure in developing countries: a review of the literature. Int J Cardiol. 2001;80(2-3):213-219.

3. Ntusi NB, Mayosi BM. Epidemiology of heart failure in sub-Saharan Africa. Expert Rev Cardiovasc Ther. 2009;7(2):169-180.

4. Onwuchekwa AC, Asekomeh GE. Pattern of heart failure in a Nigerian teaching hospital. Vasc Health Risk Manag. 2009;5:745-750.

5. Karaye KM, Sani MU. Factors associated with poor prognosis among patients admitted with heart failure in a Nigerian tertiary medical centre: a cross-sectional study. BMC Cardiovasc Disord. 2008;8:16.

6. Adewuya AO, Ola BA, Ajayi OE, Oyedeji AO, Balogun MO, Mosaku SK Prevalence and correlates of major depressive disorder in Nigerian outpatients with heart failure. Psychosomatics. 2006;47(6):479-485.

7. Obasohan AO, Ajuyah CO. How common is heart failure due to systemic hypertension alone in hospitalised Nigerians? J Hum Hypertens. 1996;10(12):801-804.

8. Levy WC, Mozaffarian D, Linker DT, et al. The Seattle Heart Failure Model: prediction of survival in heart failure. Circulation. 2006;113(11): 1424-1433.

9. Katibi IA, Beshir S, Mudashiru Z. Ambulatory 24-hour Holter electrocardiography among Nigerians: our experience at a referral cardiac centre in Lagos, Nigeria. Nigerian Medical Journal. 2006;47(2):25-27.

10. Adebola AP, Daniel FA, Lasisi GT, Ogunleye O. 24-hour Holter monitoring at the Lagos State University Teaching Hospital - a report of 85 cases. Nigerian Journal of Clinical Medicine. 2009;2(2):7-11.

11. Omokhodion SI, Jaiyesimi F, Losekoot TG. Standard 12 lead and 24 hour Holter electrocardiographic observation in a biracial group of perinatally asphyxiated newborns. West Afr J Med. 2003;22(3):253-258.

12. James PA, Oparil S, Carter BL, et al. 2014 evidence-based guideline for the management of high blood pressure in adults: report from the panel members appointed to the Eighth Joint National Committee (JNC 8). JAMA. 2014;311(5):507-520.

13. Victor RG, Kaplan NM. Systemic hypertension: mechanisms and diagnosis. In: Bonow RO, Mann DL, Zipes DP, Libby P, editors. Braunwald's Heart Disease: A Textbook of Cardiovascular Medicine. 8th ed. Philadelphia, PA: Saunders Elsevier; 2008:1027-1048.

14. Ho KK, Pinsky JL, Kannel WB, Levy D. The epidemiology of heart failure: the Framingham Study. J Am Coll Cardiol. 1993; 22(4 Suppl A):6A-13A.

15. Schocken DD, Arrieta MI, Leaverton PE, Ross EA. Prevalence and mortality rate of congestive heart failure in the United States. J Am Coll Cardiol. 1992;20(2):301-306.

16. Mann DL. Management of heart failure patients with reduced ejection fraction. In: Bonow RO, Mann DL, Zipes DP, Libby P, editors. Braunwald's heart disease. A textbook of cardiovascular medicine. 9th ed. Philadelphia: Elsevier Saunders; 2012:549-566.

17. Lang RM, Bierig M, Devereux RB, et al. Recommendations for chamber quantification: a report from the American Society of Echocardiography's Guidelines and Standards Committee and the Chamber Quantification Writing Group, developed in conjunction with the European Association of Echocardiography, a branch of the European Society of Cardiology. J Am Soc Echocardiography. 2005;18(12):1440-1463.
18. Devereux RB, Roman MJ, de Simone G, et al. Relations of left ventricular mass to demographic and hemodynamic variables in American Indians: the Strong Heart Study. Circulation. 1997;96(5): 1416-1423.

19. Devereux RB, Roman MJ, Paranicas M, et al. Relations of Doppler stroke volume and its components to left ventricular stroke volume in normotensive and hypertensive American Indians: the Strong Heart Study. Am J Hypertens. 1997;10(6):619-628.

20. Devereux RB, Alonso DR, Lutas EM, et al. Echocardiographic assessment of left ventricular hypertrophy: comparison to necropsy findings. Am J Cardiol. 1986;57(6):450-458.

21. Ajayi OE, Abiona TC, Balogun MO, Ajayi AA. Valvular regurgitation impact on left ventricular 2-dimensional and Doppler echocardiographic indices in patients with essential hypertension. J Natl Med Assoc. 2010;102(10):937-942.

22. Zoghbi WA, Enriquez-Sarano M, Foster E, et al; American Society of Echocardiography. Recommendations for evaluation of the severity of native valvular regurgitation with two-dimensional and Doppler echocardiography. J Am Soc Echocardiogr. 2003;16(7): 777-802.

23. Crawford MH, Bernstein SJ, Deedwania PC, et al. ACC/AHA guidelines for ambulatory electrocardiography: executive summary and recommendations. A report of the American College of Cardiology/ American Heart Association task force on practice guidelines (committee to revise the guidelines for ambulatory electrocardiography). Circulation. 1999;100(8):886-893.

24. Lasisi GT, Adebola AP, Ogah OS, Daniel FA. Prevalence of ventricular arrhythmias and heart rate variability pattern in chronic heart failure. Niger Postgrad Med J. 2012;19(3):157-162.

25. Lorvidhaya P, Addo K, Chodosh A, Iyer V, Lum J, Buxton AE. Sudden cardiac death risk stratification in patients with heart failure. Heart Fail Clin. 2011;7(2):157-174, vii.

26. Albert NM. Ventricular dysrhythmias in heart failure. $J$ Cardiovasc Nurs. 2004;19(6 Suppl):S11-S26.

27. Ng GA. Vagal modulation of cardiac ventricular arrhythmia. Exp Physiol. 2014;99(2):295-299.

28. Palatini P, Scanavacca G, Bongiovì S, et al. Prognostic significance of ventricular extrasystoles in healthy professional athletes: results of a 5-year follow-up. Cardiology. 1993;82(4):286-293

29. Omotoso AB, Opadijo OG, Araoye MA. Arrhythmias in hypertensive heart disease: A study of 2,017 Nigerian patients. Nig $Q J$ Hosp Med. 1997;7(4):310-313.

30. Tomaselli GF, Zipes DP. What causes sudden death in heart failure? Circ Res. 2004;95(8):754-763.

31. Erdoğan O. Holter monitoring in the prognosis of sudden cardiac death. Anadolu Kardiyol Derg. 2007;7 Suppl 1:64-67.

32. Grimm W, Christ M, Maisch B. Long runs of non-sustained ventricular tachycardia on 24-hour ambulatory electrocardiogram predict major arrhythmic events in patients with idiopathic dilated cardiomyopathy. Pacing Clin Electrophysiol. 2005;28 Suppl 1:S207-S210.

33. Hohnloser SH, Klingenheben T, Zabel M, Schöpperl M, Mauss O. Prevalence, characteristics and prognostic value during long-term follow-up of nonsustained ventricular tachycardia after myocardial infarction in the thrombolytic era. J Am Coll Cardiol. 1999;33(7): 1895-1902.

34. Sideris DA. High blood pressure and ventricular arrhythmias. Eur Heart J. 1993;14(11):1548-1553.

35. Min SS, Turner JR, Nada A, et al. Evaluation of ventricular arrhythmias in early clinical pharmacology trials and potential consequences for later development. Am Heart J. 2010;159(5):716-729.

36. Olgin J, Zipes DP. Specific arrhythmias. In: Bonow RO, Mann DL, Zipes DP, Libby P, editors. Braunwald's Heart Disease: A Textbook of Cardiovascular Medicine. 9th ed. Philadelphia, PA: Saunders Elsevier; 2012:796-798. 


\section{Publish your work in this journal}

The International Journal of General Medicine is an international, peer-reviewed open-access journal that focuses on general and internal medicine, pathogenesis, epidemiology, diagnosis, monitoring and treatment protocols. The journal is characterized by the rapid reporting of reviews, original research and clinical studies across all disease areas.

A key focus is the elucidation of disease processes and management protocols resulting in improved outcomes for the patient.The manuscript management system is completely online and includes a very quick and fair peer-review system. Visit http://www.dovepress.com/ testimonials.php to read real quotes from published authors.

Submit your manuscript here: http://www.dovepress.com/international-journal-of-general-medicine-journal 